\title{
The Epidemiology of Prostate Cancer
}

\author{
Simone Giona \\ Urology Department, Frimley Park Hospital, Portsmouth Rd, Frimley, \\ Camberley GU16 7UJ, UK
}

Author for correspondence: Simone Giona, Urology Department, Frimley Park Hospital, Portsmouth Rd, Frimley, Camberley GU16 7UJ, UK.

Email: simone.giona@nhs.net

Doi: https://doi.org/10.36255/exonpublications.prostatecancer.epidemiology.2021

\begin{abstract}
Prostate cancer is the third most common diagnosed malignancy. It is a heterogeneous disease with incidence rates that vary substantially across the world, from 6.3 to 83.4 per 100,000 people. Age-standardized incidence rates are the highest in Northern Europe and lowest in South Central Asia. Men of African origin are more prone to the disease compared with other ethnicities. Mortality rates differ significantly from incidence rates, with the highest figures in the Caribbean, Sub-Saharan Africa and Micronesia/Polynesia. This chapter provides an overview of the global trends in epidemiology of prostate cancer. Incidence and mortality rates in the Americas, Africa, Europe, Asia, and Oceania are presented.
\end{abstract}

Keywords: epidemiology; incidence; mortality; prostate cancer; prostate-specific antigen

In: Prostate Cancer. Bott SRJ, Ng KL (Editors). Exon Publications, Brisbane, Australia. ISBN: 978-0-6450017-5-4; Doi: https://doi.org/10.36255/exonpublications.prostatecancer.2021

Copyright: The Authors.

License: This open access article is licenced under Creative Commons Attribution-NonCommercial 4.0 International (CC BY-NC 4.0) https://creativecommons.org/licenses/by-nc/4.0/ 


\section{INTRODUCTION}

In 2020, according to the World Health Organisation (WHO), prostate cancer is the third most common diagnosed malignancy. With $1,414,259$ cases $(7.3 \%$ of the total), prostate cancer is preceded only by lung and colorectal cancer with $2,206,771$ and $1,148,515$ cases respectively (11.4 and 10.0\%) (1). It is the most commonly diagnosed cancer in over $50 \%$ of countries in the world (112 of 185) and its incidence varies substantially between countries with a high Human Development Index (HDI) and those with a low HDI, 37.5 vs 11.3 per 100,000 people, respectively. Mortality rates are less variable (8.1 vs 5.9 per 100,000 people). Prostate cancer is a heterogeneous disease with incidence rates that vary substantially across the world from 6.3 to 83.4 per 100,000 people. The regions with highest figures are Northern and Western Europe, the Caribbean, Australia/ New Zealand, North America and Southern Africa (Figure 1). The lowest are found in Asia and North Africa. However, cases are increasing in Asian countries such as Japan and Singapore where, historically, this cancer had a low incidence rate and prostate-specific antigen (PSA) testing was minimal (2). Mortality rates differ significantly from incidence rates, with the highest figures in the Caribbean (75.8 per 100,000 people), Sub-Saharan Africa (22.0 per 100,000 people) and Micronesia/Polynesia (18.8 per 100,000 people) (1). This chapter provides an overview of the global incidence and mortality of prostate cancer.

\section{PROSTATE CANCER IN THE USA}

The most recent statistics published on prostate cancer by the National Center for Health Statistics (NCHS), USA, includes data from 1930-2017. This is due to a delay between data collection and analysis of about 3-4 years. Based on this assumption, the AMC (American Cancer Society) made the following prediction for 2020: (i) 606,520 total cancer deaths, of which, 33,330 (5.5\% of total) were expected to be from prostate cancer; and (ii) 1,806,590 new cases of cancer, of which, 191,930 are prostate cancers (10.6\%). Prostate cancer is the third most common tumor after lung and colon cancer, and the second most deadly after lung cancer. According to the SEER model (Surveillance, Epidemiology and End Results), the lifelong probability of an American developing an invasive prostate cancer is 11.6 ( 1 in 9) (3).

The incidence of prostate cancer is strongly correlated to the changes in medical practice and PSA monitoring programs. The early 1990s witnessed a sharp increase in cases. This was due to the widespread introduction of PSA monitoring (formally approved by FDA in 1986), which dramatically increased the detection of asymptomatic disease (4). Those figures then declined quite suddenly between 2007 and 2014 and stabilized around 2016. Prostate cancer incidence rates constantly declined by $6.5 \%$ per year from 2007 for all races combined. In contrast, for advanced stage disease, there was an inflection point involving all racial groups and ages (5). The explanation could partially rely on the fact that in 2012, the US Preventing Services Task Force recommendations were changed against routine PSA testing (Grade D) due to concerns about prostate cancer overdiagnosis and overtreatment $(6,7)$. Thus, after years of 'excitement', clinicians started testing 


\section{Prostate}

\section{Northern Europe \\ Western Europe \\ Caribbean}

Australia/New Zealand

Northern America

Southern Africa

South America

Southern Europe

Micronesia/Polynesia

Eastern Europe

Central America

Middle Africa

Melanesia

Western Africa

Western Asia

Eastern Africa

Eastern Asia

Northern Africa

South-Eastern Asia

South Central Asia

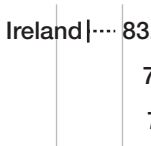

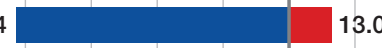

77.6

75.8

75.8

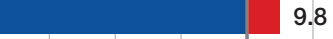

9.8

27.9

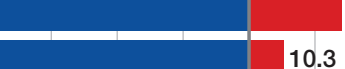

$73.0 \square 8.3$

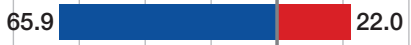

62.5

13.6

\begin{tabular}{l|l}
59.1 & 7.8
\end{tabular}

56.5

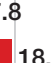

13.7

46.4

43.8

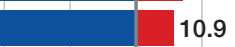

40.8

24.8

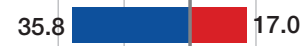

33.1

20.2

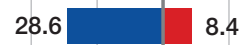

27.9

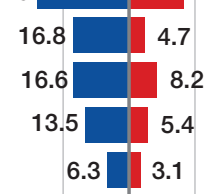

$16.3 \cdots \mid$ Zimbabwe

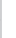

1

$40 \quad 80 \quad 120$

\section{Age-standardized (W) rate per 100,000}

Mortality

Figure 1. Region-specific incidence and mortality. Age-standardized rates for prostate cancer in 2020. Rates are shown in descending order of the world (W). Age-standardized incidence rate, and the highest national age-standardized rates for incidence and mortality are superimposed. Source: GLOBOCAN 2020. https://gco.iarc.fr [Accessed on 06 April 2021].

less and less patients. However, the increase in advanced stage diagnosis cannot completely be explained by the change in PSA screening protocols (Figure 2).

As explained by Negoita in his paper in 2018, those figures could also be partially explained by improved staging workup or better stage documentation (5). In 2018, the same US Task force revised their recommendation to "informed decision making" for men between 55 and 69 years (Grade C). This was due to updated evidence that showed "a small potential benefit" of reduced prostate mortality in some men $(8,9)$. An important remark must be made regarding prostate cancer incidence and ethnicity. Much research has shown that the incidence of prostate cancer is greatest in African American men (1). This demographic is generally more likely to develop prostate cancer at any age and develop the cancer earlier in life than men of any other racial or ethnic group (Figure 3). Studies have been done to compare incidence rates of the same ethnic group between different 

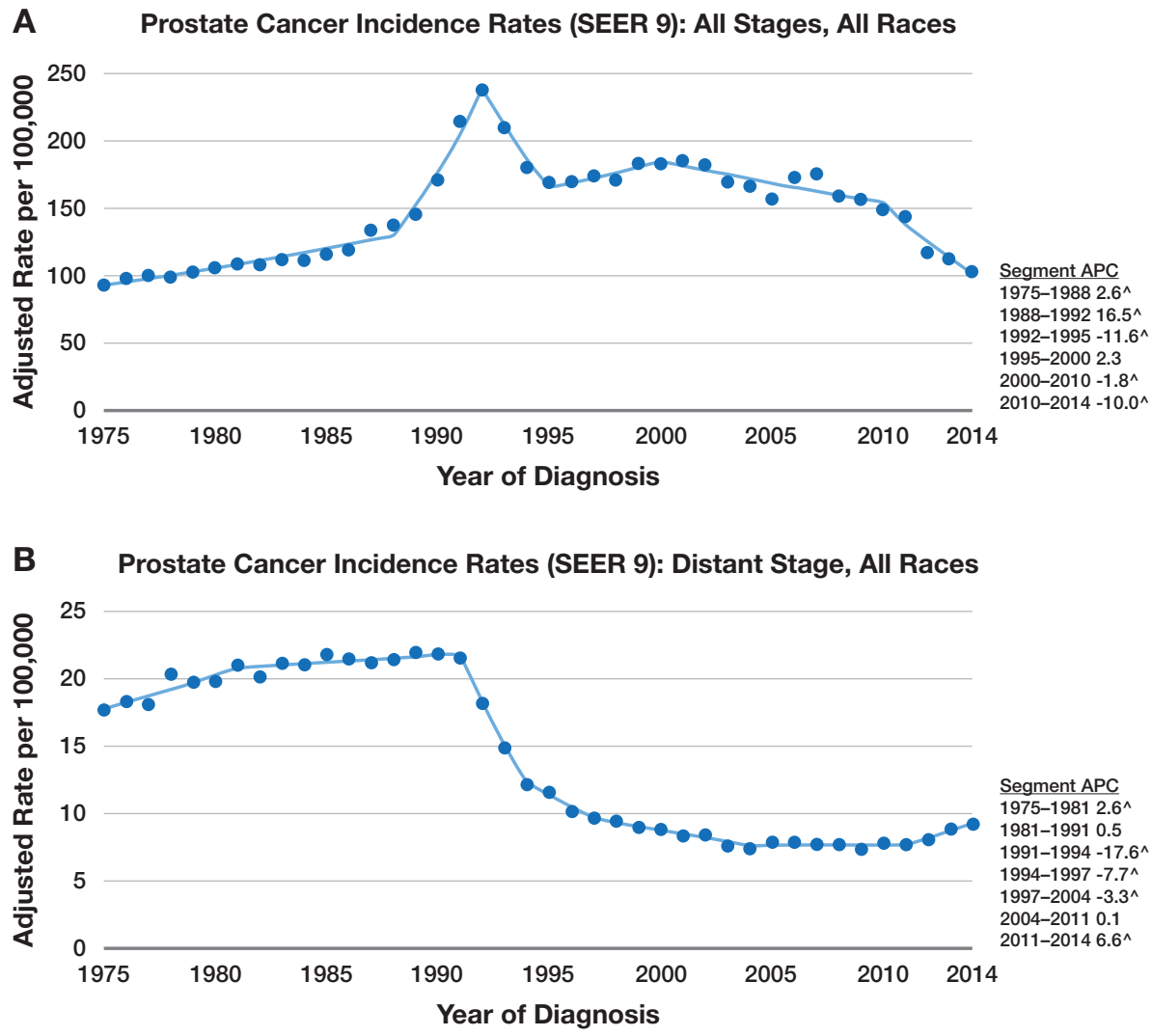

Figure 2. Prostate cancer incidence rates (SEER 9). A. All stages and all races. B. Distant stage and all races. Rates are per 100,000 persons and have been age-adjusted to the 2000 US standard population and delay-adjusted for age and stage at diagnosis. APC (annual percent change); SEER, Surveillance, Epidemiology, and End Results. Source: Negoita et al. (5). Annual report to the Nation on the status of Cancer, Part II: Recent changes in prostate cancer trends and disease characteristics.

countries, but it has revealed to be difficult due to differences in data collection and detection pathways (10).

Looking at the 1975-2017 data provided by the NCHS, we can see that there has been a slow increase in mortality since 1987, with an annual percent change (APC) of 0.9, reaching its peak between 1987 and 1991 with an APC of 3 for all races and 3.1 for white men. This peak was slightly delayed for black men, peaking in 1988 (APC 3.3). The highest mortality for all races was observed between 1975 and 2015, especially in 1993 (39.3 per 100,000 people). Again, mortality for black men reached its highest point in 1993 (81.9 per 100,000 people), two years after the peak for white men (36.5 per 100,000 people) (5). Since then, a steady decrease in mortality was observed: 1991-1994 (APC -0.5); 1994-1998 (APC -4.2); 1998-2013 (APC -3.5); and 2013-2017 (APC -0.3). A higher decline 


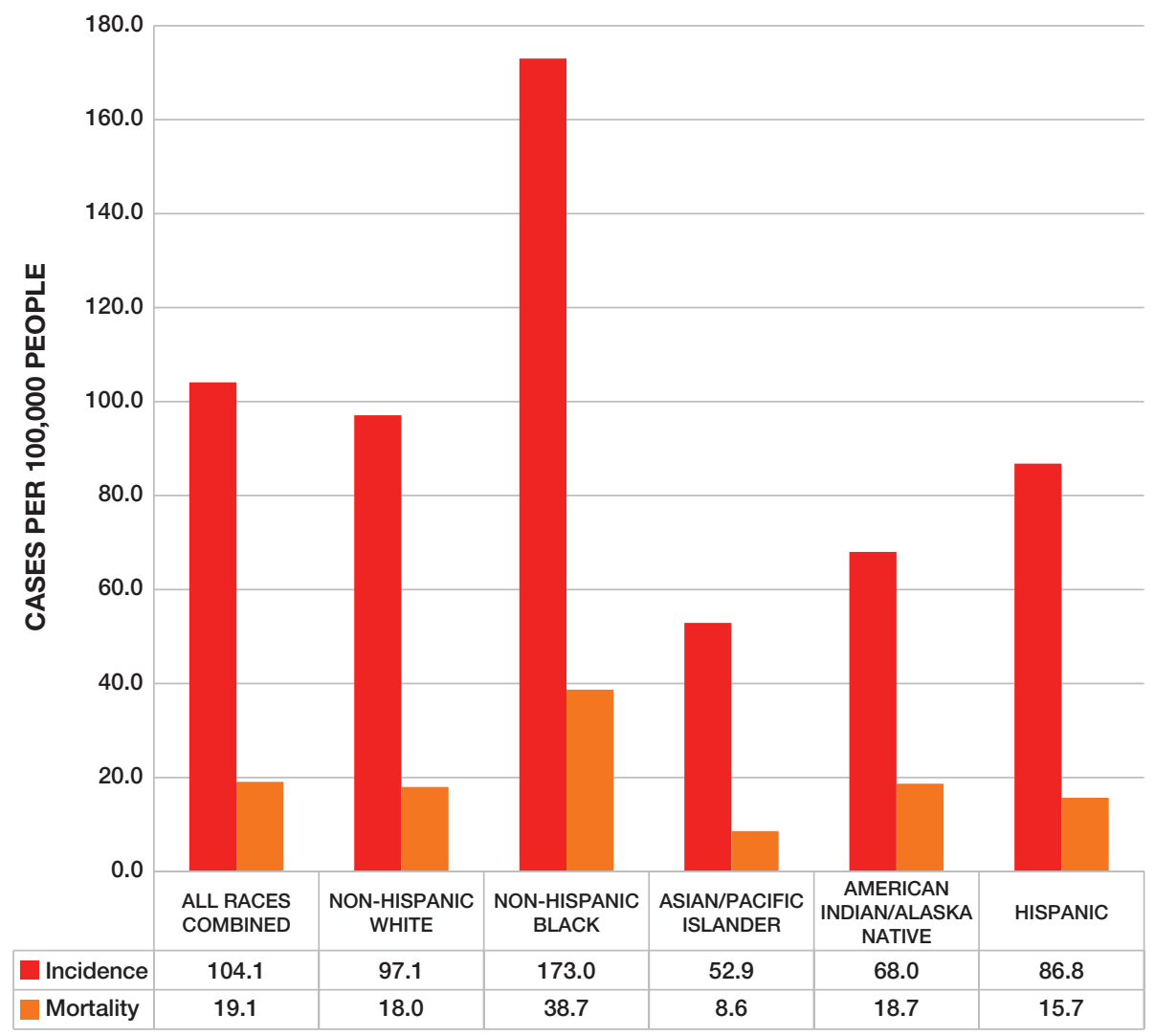

Figure 3. Prostate cancer incidence and mortality Rates. By race and ethniciy, United States, 2012 to 2017. Source: Siegel et al. (19) Cancer Statistics 2020.

in mortality was observed in black men (APC -2.5) compared to white men (APC -0.7). During 2001-2015, the rate of mortality decreased among black men with an APC of $-4.2(5)$.

\section{PROSTATE CANCER IN THE AMERICAS OTHER THAN THE USA}

Canada showed an increase in crude prostate cancer incidence/diagnosis rates during $1992-2010$ by $1.70 \pm 0.30$ cases per 100,000 males per year. However, if the data are age-adjusted, no significant increase in incidence rates were noted. Over the same period Canada witnessed 69,655 deaths, with an overall decline. Crude mortality rates reduced by $-0.19 \pm 0.022$ deaths per 100,000 males per year between 1992 and 2010, significantly lower in the quintile with the highest percentage of African-Canadian/Black individuals (11). 
Columbia, Costa Rico, and Ecuador witnessed an increase in prostate cancer incidence during 1993-2002. Incidence rates in Brazil have been relatively high but remained stable in more recent years, following an increase in 2012 (12). According to GLOBOCAN 2008, the incidence of prostate cancer in South America was 50.2 cases per 100,000. These figures rose to 59.2 in $2020(12,13)$. Mortality trends in the Americas are difficult to analyze due to the heterogeneity and lack of data available. Rates are increasing in Brazil, Colombia and Ecuador, decreasing in Argentina, Costa Rica and Chile, and stable in Mexico (12). The lowest mortality was observed in Brazil and Mexico (12-13 per 100,000 people) in 2000. In 2020, the overall mortality rate for prostate cancer in the Americas was 14.2 cases per 100,000 people a slight reduction when compared to the 16.2 case per 100,000 observed in $2008(12,13)$. Unfortunately, due to the lack of resources, no regular screening plans are active in south America with the exception of the Barretos Cancer Hospital in Brazil, which has a program that offers screening for prostate cancer (PSA and DRE) as well as screening for other common types of cancer (ie, skin, breast, and cervix) using mobile units in 231 municipalities from 6 states. From January 2004 to December 2007, 17,571 men, 45 -years-old,were screened and 652 prostate cancer cases were identified, mostly with localized disease (93.4\%).

\section{PROSTATE CANCER IN CENTRAL AMERICA/CARIBBEAN}

The Caribbean has one of the highest rates of prostate cancer worldwide. Incidence rates have been registered as high as 304 cases per 100,000 (14-16). Hennis et al. reported an overall crude incidence rate of 131.0 (95\% CI: 123.4- 139.0) per 100,000 men; when data were standardized to the US, European, or World populations, this was 160.4 (95\% CI: 151.0- 170.2), 163.1 (95\% CI: 153.4-173.3), and 112.0 (95\% CI: 105.2-119.3) per 100,000 men (17). Stratifying by age, it was noted that, prostate cancer incidence increased from 6.0 (95\% confidence interval: $1.6-15.3$ ) per 100,000 men at ages 40 to 44 years to $1,026.6$ (95\% CI: 898.8-1,167.6) per 100,000 in men aged 70 to 74 years, and declined thereafter (17). In the paper, it was also noted that, differently from the USA, where socioeconomic and health-care access issues need to be considered, Barbados provides free access to healthcare. However, it must be taken into consideration that the information provided by the Public Health services of the area are often imprecise and sparse, and therefore it is particularly challenging to generate and provide reliable data. For the period 2003-2007, Gibson and Gibson reported that the Jamaican age-standardised rate (ASR) for prostate cancer was 78.1 per 100,000 persons which is a substantial increase when comparted to 65.5 per 100,000 people of the period 1998-2002 (15). Prostate cancer mortality in Trinidad and Tobago has been registered among the highest in the world, with an annual increase in mortality by $4.5 \%$ over the last decade (12). For Barbadian men, mortality ranged from 63.2 to 101.6 per 100,000 persons between 1995-2008 (17). In 2020, the IARC (International Agency for Research on Cancer) provided similar figures to those of Gibson and Gibson with an ASR incidence of 75.8 cases per 100,000 people, whereas the mortality was 27.9 cases per 100,000 people (13). 
Among the Central American countries, Costa Rica leads with an ASR (age standardised to World Population rate) of 53.8 cases per 100,000 people, followed by Mexico and Cuba with 28.9 and 24.3 cases per 100,000 people respectively (18). Unfortunately, epidemiological data are scarse for those regions. Trends are available only for Costa Rica which showed an annual increase in incidence of $3.8 \%$ per annum over the period 1997-2008. ASR on mortality put Belize at first place with 28.9 cases per 100,000 people followed by Cuba and Mexico with 24.1 and 17.0 cases per 100,000 people for the period 2003-2010, respectively. Costa Rica stops at 14.8 cases per 100,000 people (19). The most recent data on Central America published by GLOBOCAN 2020 shows an ASR incidence of 43.8 and mortality of 11.0 cases per 100,000 people (13). No active screening program are currently in place in Central America. Between 2004 and 2006, in Monterrey (Mexico) a screening program was run, using PSA and DRE; screening of 973 men, 40 years of age, showed that only 44\% (55/125) of the men who had an abnormal result underwent prostate biopsy, and 27\% (15/55) of these were diagnosed with prostate cancer, mostly with high grade lesions (based on Gleason scores 7) (18).

\section{PROSTATE CANCER IN AFRICA}

The incidence of prostate cancer in Africa is belived to be high. As it has been shown in many publications, prostate cancer is the leading cancer in terms of incidence and mortality in men of African origin. However, data is fragmented and incomplete. According to Echinemane et al. prostate cancer is more common than liver cancer, non-Hodgkin's lymphoma, and lung cancer in Abidjan, Ivory Coast (20). In contrast, Chu et al. demonstrated that prostate cancer incidence among African Americans was as much as 40 times higher than black men in Africa (21). The highest rates were reported in East Africa with figures of 10.7-38.1 per 100,000 people and the lowest rates were reported in West African countries, at 4.7-19.8 per 100,000 people. However, data collection and PSA testing are both minimal in the continent, thus severely affecting the reliability and statistical analysis of the data.

Prostate cancer is becoming more and more an issue of public concern in Africa due to the fact that the majority of new diagnoses are advanced/metastatic cancers, with poor prognosis and low chances of long-term survival. About $64 \%$ of new prostate cancer cases in a Nigerian hospital had advanced disease and died within two years of diagnosis. Those figures are dismal when compared to the American data. For comparison, in the United States, 66\% of the patients who had a diagnosis of prostate cancer in 1975 survived more than 5 years while between 2008 and 2014 that number rose to 98.2\% (22). In 2010, Ferlay et al. estimated that 57,048 deaths will be caused by prostate cancer in Africa by 2030. This represents a $104 \%$ increase over the next 10 years (23). According to the data provided by the IARC 2020, ASR of incidence and mortality for prostate cancer in the African continent were respectively 29.7 and 16.3 cases per 100,000 people. 


\section{PROSTATE CANCER IN EUROPE}

Due to the availability of more comprehensive information, data from the United Kingdom (UK) are discussed separately from the other European countries.

\section{United Kingdom}

Currently, PSA screening is not offered in UK as part of early prostate cancer detection. Cancer Research UK advises that men 50-years or older can request screening through their general practitioner, where a discussion about risks and benefits will be made. According to the most recent data, prostate cancer is the most common cancer diagnosed in men in the UK, representing $26 \%$ of all new diagnoses in 2017 (24). For males aged 45 years and over, prostate cancer was the most common cancer, peaking at $32.8 \%$ of all cancers in the 65-74 age group. Considering age-specific incidence, prostate cancer rates rise steeply from around age 50-54, peak in the 75-79 age group before dropping slightly and remaining stable in the oldest age groups. The highest figures are in the 75 to 79 age group as shown in Figure 3. Between 1993-1995 and 2015-2017, the European age standardised incidence rates of prostate cancer increased by $41 \%$, with a 4\% increase between 2005-2007 and 2015-2017. The percentage increase for each age group is: 50-59 (291\%), 60-69 (137\%), and 70-79 (41\%). In contrast, in the oldest group (over 80 ), the incidence decreased by $28 \%$. These numbers are likely secondary to random findings due to PSA testing, incidental detection of asymptomatic disease and the increase of benign prostatic hyperplasia procedures such as transurethral resection of the prostate (TURP) and its histological findings (24). An important factor that must be taken into account is the ethnic heterogeneity of prostate cancer across the UK population. According to "The PROCESS Cohort Study" published in 2008, Afro-Caribbean men had an age-adjusted prostate cancer incidence rate of 173 per 100,000 people compared to a rate of 56.4 per 100,000 for UK white men and 139 for black African men. Moreover, it was found that Afro-Caribbean men residing in the UK were three times more likely to be diagnosed with the disease and were diagnosed 5 year earlier than Caucasian men residing in the UK, despite both groups having equal access to diagnostic services (25). In conclusion, the lifetime risk of being diagnosed with prostate cancer is $13.2-15.0 \%$ for white males, while in black males it is significantly higher (23.5-37.2\%), and in Asian males it is significantly lower (6.3-10.5\%) (26).

During the 1990s, PSA testing was introduced; it showed a 10-fold difference in uptake in the UK compared to the USA. For Comparison, in 2001, in the USA, $57 \%$ of men aged 50 years or older reported having a PSA test within the previous 12 months. By contrast, for each year between 1999 and 2002, an estimated 6\% of men aged 45-84 years were tested in the UK (27).

Despite those differences, Colling et al. showed that although age-adjusted prostate cancer mortality reached its maximum in early 1990s at almost identical rates, there was not a similar decrease in mortality in the UK that was seen in the USA. From the mid-1990s, Age-adjusted prostate-cancer mortality declined in the USA by $4.17 \%$ each year between 1994 and 2004, almost four-times the rate of decline in the UK (1.14\% each year), especially in patients aged 75 years or 
older (27). This data may be explained by a general tendency in the USA to treat prostate cancer more aggressively than in the UK. The most recent figures (2016-2018) showed that every year in UK, around 11,900 men die of prostate cancer. Those figures represented 13\% of all cancer deaths in males in the UK in 2018 (24). However, as can be seen from Figure 4 over the last decade (between 2006-2008 and 2016-2018), prostate cancer age-standardized mortality rates for males decreased by $10 \%$. According to the data provided by Cancer Research UK, mortality rates for prostate cancer are projected to fall by $16 \%$ in the UK between 2014 and 2035, to 48 deaths per 100,000 males by 2035 .

\section{Prostate cancer in other European countries}

A general increase in prostate cancer has been witnessed in Western Europe (28). It is unclear if these figures are secondary to PSA screening or other factors such as diet and low exposure to sunlight (Vitamin D) (29). Since mid 1990, an increase of APC between 4 and 5\% has been witnessed in Austria, France, and Switzerland. Figures remained stable in other countries such as Netherlands from 1999 to 2008. According to Center et al. (12), mortality rates decreased in Austria, France, Switzerland, Germany and Netherlands. The main decline was seen in Austria (APC 4.0) whereas the lowest in Germany and Netherlands (APC 2.3). In Southern Europe, an overall increase in prostate cancer was recorded between
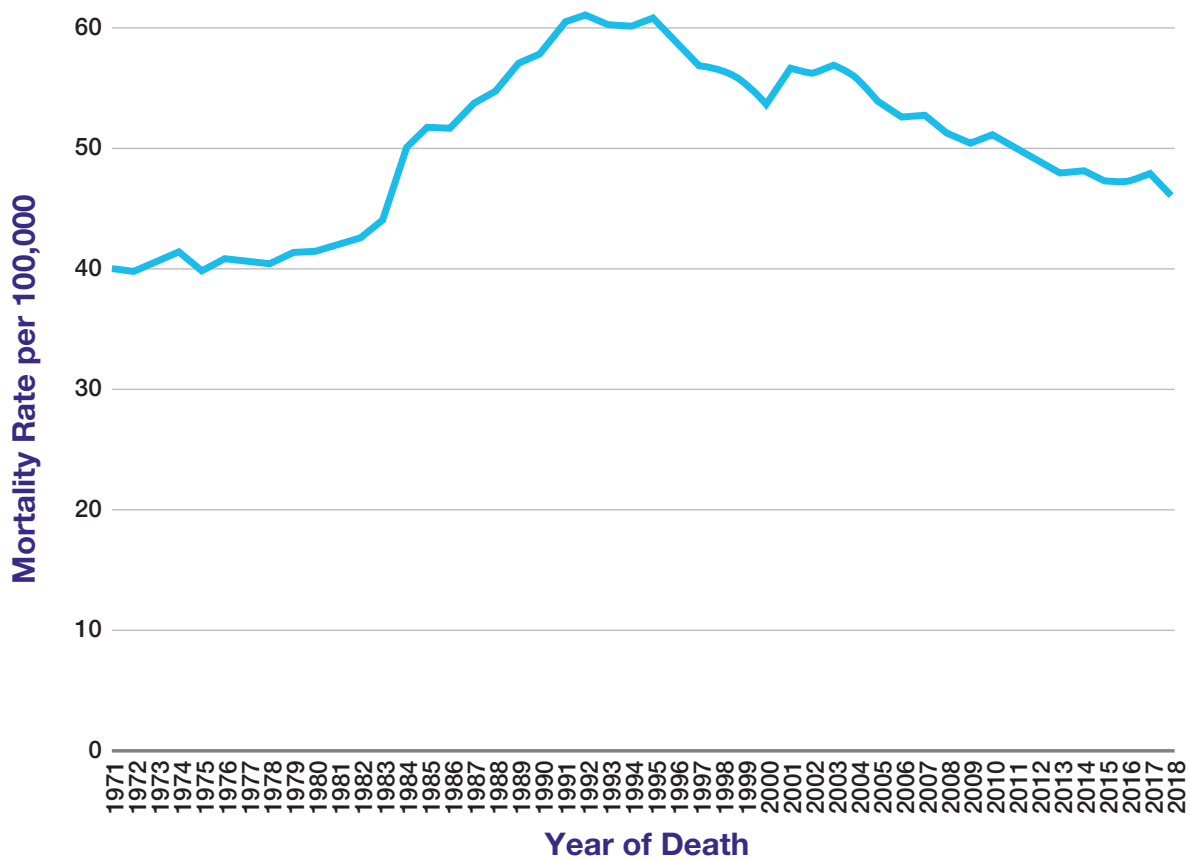

Figure 4. Prostate cancer moratlity. European age-standardised mortality rates per 100,000 population, Males, UK, 1971-2018. Source: https://www.cancerresearchuk.org [accessed on 06 April 2021]. 
1998 and 2007. The largest increase was seen in Croatia (APC 8.5\%) followed by Italy, Slovenia, Malta and Spain. Mortality rates were more heterogenous with decline seen in Italy, Malta, Spain and increase in Croatia and Slovenia (28). An increase in prostate cancer incidence was recorded over the past decade in four out of the five Nordic countries (Denmark, Iceland, Norway, and Sweden). The most relevant increase was in Denmark (APC 8.2\% between 1999 and 2008). Finland showed stable figures. In terms of mortality, a stable trend was seen in Denmark and Iceland whereas Norway and Sweden experienced a substantial decrease. In Finland, a decrease of 3.1\% per annum has been seen since $2000(12,28)$.

\section{PROSTATE CANCER IN RUSSIA AND FORMER SOVIET UNION COUNTRIES}

This section analyses the incidence and mortality of prostate cancer in the Baltic States, Belarus, Russian Federation and Ukraine. It should be pointed out that these countries have very different profiles of PSA testing uptake. The Russian Federation was the first to introduce PSA testing in the 1990. Since 2013, PSA is part of a national health check-up program. Lithuania introduced the test in 2000. A nationwide PSA screening program has been introduced since 2006. By 2010 around $72-78 \%$ of the total eligible male population received a PSA test. In Latvia, PSA testing has not been funded by the Government. A recent review by Patasius et al. showed that the countries can be divided in two groups (30): high (>100 cases per 100,000 people), and low ( $<100$ cases per 100,000 people) incidence countries. The Baltic States (Estonia, Latvia, and Lithuania) belong to the former whereas Belarus, the Russian Federation and Ukraine to the latter. Lithuania is the country with the highest incidence overall (203.4 per 100,000 people) followed by Estonia and Latvia (158.3 and 102.2 per 100,000 people, respectively). In the Russian Federation, figures are low (55.2 per 100,000 people) as it is for Ukraine (36.2 per 100,000 people). A recent study showed that the APC of prostate cancer has been constantly positive for all years; however, the inconsistency of cancer databases (1978 to 2016 in Lithuania and 2000-2012 in Ukraine) should be taken into account. The APC ranges from 3.4 to 7.4 for Ukraine and Lithuania, respectively. In Estonia and Lithuania, incidence peak for men aged 50-74 was in 2007, followed by an incidence decrease in Lithuania since 2007 and Estonia since 2011.

Despite remarkable differences in incidence, mortality rates among all countries are relatively similar. The highest figures were recorded in Lithuania (ASR of 26.68, 1995-1999) and the lowest in the Russian Federation (ASR of 12.24 in the same period). Age-specific mortality was the highest in the over 85 age group. During 2011-2015, the mortality rates in this group doubled. However, the relative difference between the Baltic states and other countries remained unchanged (30). The reason behind the high mortality rates after the implementation of the PSA-based screenings is unclear. It is possible that these figures are secondary to over-reporting of prostate cancer as the underlying cause of death in death certificates. A similar issue was noted in the USA in 1991, a few years after the implementation of PSA screening (31). 


\section{PROSTATE CANCER IN ASIA}

The incidence of prostate cancer in Asian countries has been historically much lower than their Western counterpart, ranging between 4.5 cases per 100,000 persons for South-Central Asia, 10.5 for Eastern Asia and 11.2 for Southeast Asia (12). Those values could be explained both by a low susceptibility of Asian men to prostate cancer and the lack of a systematic screening program. However, there is evidence that these figures are increasing in several countries (23). A review by $\mathrm{Ha}$ Chung et al., showed a general increase in prostate cancer incidence across China, India, South Korea, Vietnam, Japan, and Singapore (32). These figures were supported by data from GLOBOCAN 2008 and 2012 (23, 32). Sim and Cheng noted that in some centres in Japan, the incidence rate rose from 6.3 to 12.7 (102\% increase) between 1978 and 1997, while the incidence rates in Singaporean Chinese men increased to $118 \%$ (from 6.6 to 14.4 case per 100,000 people) within the same period (33). The lowest incidence reported in Asia was in Shanghai whereas the highest was in the Rizal Province in the Philippines. Figure 5 shows the differences in incidence and mortality across Asia. Studies have also shown that Asian Men living in the United States develop higher risk of prostate cancer than their counterparts living in Asia suggesting that change in lifestyle, and probabaly increased screening, could be the major contributors (34).

In 2008, prostate cancer accounted for about $2 \%$ of all cancer-associated deaths in the Asia-Pacific. In the same period, over 250,000 men died of prostate cancer around the globe, of which, 42,000 (16\%) deaths occurred in the

\section{Prostate Cancer incidence and mortality in Asian Regions 2012}

30.0

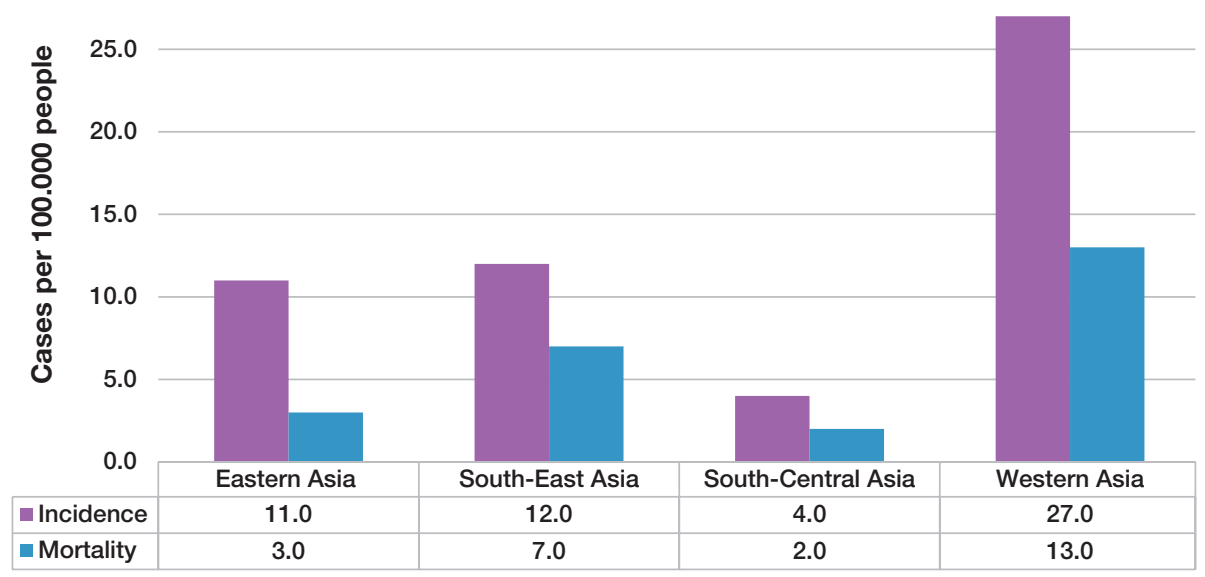

Figure 5. Incidence and mortality rates (per 100,000) in different Asian regions in 2012. Data source: GLOBOCAN 2012 v1.0, Cancer Incidence and Mortality Worldwide: IARC Cancer Base No. 11. Source: Adapted from Chen et al., 2014, "Prostate Cancer in Asia: A Collaborative Report." 
Asia-Pacific area. China accounted for 34\% of prostate cancer deaths, Japan 24\%, and Indonesia 16\% (34). In addition, it was noted that in Asian countries, despite having a 20 times lower incidence rate than USA, prostate cancer mortality was only about $2.5 \%$ lower than the USA. A useful tool that can be used is the mortality rate to incidence rate ratio, MR/IR. In 2012, the MR/IR in Asia was between 0.3 and 0.6 whereas it was 0.1 in the USA and 0.18 in Europe (35). This disparity between IR and MR could be explained by the lack of screening tools and the consequent delayed diagnosis in Asia compared to Western countries. In view of these results, Zhang et al. suggested that it would be wise and useful to integrate PSA screening, as well as develop a nationwide cancer registration system (35).

\section{PROSTATE CANCER IN OCEANIA AND NEW ZEALAND}

Australia approved the use of PSA in 1989, similarly to the USA. The introduction of this test caused a steep increase in the lifelong risk of detecting prostate cancer from the 6.1\% of 1982 (1 in 17) to 18.4\% of 1994 (36). In 1996, the Australian Health Advisor Committee recommended against screening asymptomatic men for prostate cancer. Between 2008 and 2009, 21-25\% of the Australian men aged 50-75 had a PSA test (37). In 2012, the introduction of the American USPSTF recommendation against PSA testing caused a further reduction in screening. The impact of the 2018 USPSTF has not been studied yet in the country. Overall, the lifetime risk of prostate cancer has shown some fluctuations after the years, but has never dipped below 15\%, and in 2012 it was 19.7\% (95\% CI $19.4 \%$ to $20 \%$ : 1 in 5) (36). According to IARC 2008, the prostate cancer ASR incidence was 94.5 per 100,000 persons, which dropped to 70 per 100,000 in 2020 (1). Mortality rates decreased in Australia by 2.3\% between 1995 and 2004 and by 2.8\% per year on average in New Zealand (12). According to GLOBOCAN, the ASR mortality secondary to prostate cancer was 15.3 cases per 100,000 people in 2008 (12) and 15.3 per 100,000 people in 2020 (1).

\section{CONCLUSION}

Prostate cancer is one of most common cancers diagnosed worldwide. With more than $1,400,000$ ( $>7 \%$ ) new cases and more than 375,000 (3.8\%) deaths annually, it is the third most common malignancy diagnosed, and is the eighth cause of cancer death. Its incidence varies greatly between regions of the World, and is hugely affected by PSA testing and related screening programs.. It has been demonstrated that wherever screening is available, the incidence increases without necessarily seeing associated steady decrease in cancer specific mortality. Currently, there is no international consensus on the best approach on PSA testing. It is well known and documented that men of African origin are more prone to develop prostate cancer over the course of their life, whereas Asian ethnicities seems to be less affected. The reason behind those differences is still unclear, but is likely to be multifactorial. 
Conflict of interest:The author declares no potential conflicts of interest with respect to research, authorship and/or publication of this article.

Copyright and permission statement:The author confirms that the materials included in this chapter do not violate copyright laws. Where relevant, appropriate permissions have been obtained from the original copyright holder(s), and all original sources have been appropriately acknowledged or referenced.

\section{REFERENCES}

1. Sung H, Ferlay J, Siegel RL, Laversanne M, Soerjomataram I, Jemal A, et al. Global cancer statistics 2020: GLOBOCAN estimates of incidence and mortality worldwide for 36 cancers in 185 countries. CA: a cancer journal for clinicians. 2021. https://doi.org/10.3322/caac.21660

2. Baade PD, Youlden DR, Krnjacki LJ. International epidemiology of prostate cancer: geographical distribution and secular trends. Mol Nutr Food Res. 2009;53(2):171-84. https://doi.org/10.1002/ mnfr.200700511

3. Surveillance E, and End Results (SEER) Mortality - All COD, Aggregated With State, Total U.S. (1969-2017)<Katrina/Rita Population Adjustment>, National Cancer Institute, DCCPS, Surveillance Research Program, released December 2019. Underlying mortality data provided by NCHS (www. cdc.gov/nchs) [Accessed on 06 April 2021].

4. Potosky AL, Miller BA, Albertsen PC, Kramer BS. The role of increasing detection in the rising incidence of prostate cancer. JAMA. 1995;273(7):548-52. https://doi.org/10.1001/ jama.1995.03520310046028

5. Negoita S, Feuer EJ, Mariotto A, Cronin KA, Petkov VI, Hussey SK, et al. Annual Report to the Nation on the Status of Cancer, part II: Recent changes in prostate cancer trends and disease characteristics. Cancer. 2018;124(13):2801-14. https://doi.org/10.1002/cncr.31549

6. Siegel RL, Miller KD, Jemal A. Cancer statistics, 2016. CA: a cancer journal for clinicians. 2016;66(1):7-30. https://doi.org/10.3322/caac.21332

7. Moyer VA, Force USPST. Screening for prostate cancer: U.S. Preventive Services Task Force recommendation statement. Ann Intern Med. 2012;157(2):120-34. https://doi. org/10.7326/0003-4819-157-2-201207170-00459

8. Bibbins-Domingo K, Grossman DC, Curry SJ. The US Preventive Services Task Force 2017 Draft Recommendation Statement on Screening for Prostate Cancer: An Invitation to Review and Comment. JAMA. 2017;317(19):1949-50. https://doi.org/10.1001/jama.2017.4413

9. Fenton JJ, Weyrich MS, Durbin S, Liu Y, Bang H, Melnikow J. Prostate-Specific Antigen-Based Screening for Prostate Cancer: Evidence Report and Systematic Review for the US Preventive Services Task Force. JAMA. 2018;319(18):1914-31. https://doi.org/10.1001/jama.2018.3712

10. Kheirandish P, Chinegwundoh F. Ethnic differences in prostate cancer. Br J Cancer. 2011;105(4):481-5. https://doi.org/10.1038/bjc.2011.273

11. Lagace F, Ghazawi FM, Le M, Savin E, Zubarev A, Powell M, et al. Incidence and Mortality of Prostate Cancer in Canada during 1992-2010. Curr Oncol. 2021;28(1):978-90. https://doi.org/10.3390/ curroncol28010096

12. Center MM, Jemal A, Lortet-Tieulent J, Ward E, Ferlay J, Brawley O, et al. International variation in prostate cancer incidence and mortality rates. Eur Urol. 2012;61(6):1079-92. https://doi. org/10.1016/j.eururo.2012.02.054

13. IARC. Estimated age-standardized incidence rates (World) in 2020, worldwide, all ages. 2020.

14. Bunker CH, Patrick AL, Konety BR, Dhir R, Brufsky AM, Vivas CA, et al. High prevalence of screening-detected prostate cancer among Afro-Caribbeans: the Tobago Prostate Cancer Survey. Cancer Epidemiol Biomarkers Prev. 2002;11(8):726-9. 
15. Gibson TN, Hanchard B, Waugh N, McNaughton D. Age-specific incidence of cancer in Kingston and St. Andrew, Jamaica, 2003-2007. West Indian Med J. 2010;59(5):456-64.

16. Glover FE, Jr., Coffey DS, Douglas LL, Cadogan M, Russell H, Tulloch T, et al. The epidemiology of prostate cancer in Jamaica. J Urol. 1998;159(6):1984-7. https://doi.org/10.1016/S0022-5347(01)63220-8

17. Hennis AJ, Hambleton IR, Wu SY, Skeete DH, Nemesure B, Leske MC. Prostate cancer incidence and mortality in barbados, west indies. Prostate Cancer. 2011;2011:565230. https://doi. org/10.1155/2011/565230

18. Sierra MS, Soerjomataram I, Forman D. Prostate cancer burden in Central and South America. Cancer Epidemiol. 2016;44 Suppl 1:S131-S40. https://doi.org/10.1016/j.canep.2016.06.010

19. Siegel RL, Miller KD, Jemal A. Cancer statistics, 2020. CA: a cancer journal for clinicians. 2020;70(1):7-30. https://doi.org/10.3322/caac.21590

20. Echimane AK, Ahnoux AA, Adoubi I, Hien S, M'Bra K, D'Horpock A, et al. Cancer incidence in Abidjan, Ivory Coast: first results from the cancer registry, 1995-1997. Cancer. 2000;89(3):653-63. https://doi.org/10.1002/1097-0142(20000801)89:3<653::AID-CNCR22>3.0.CO;2-Z

21. Chu LW, Ritchey J, Devesa SS, Quraishi SM, Zhang H, Hsing AW. Prostate cancer incidence rates in Africa. Prostate Cancer. 2011;2011:947870. https://doi.org/10.1155/2011/947870

22. Howlader N, Noone A, Krapcho M, Miller D, Bishop K. SEER Cancer Statistics Review 1975-2013. National Cancer Institute, Bethesda MD; 2016.

23. Ferlay J, Shin HR, Bray F, Forman D, Mathers C, Parkin DM. Estimates of worldwide burden of cancer in 2008: GLOBOCAN 2008. Int J Cancer. 2010;127(12):2893-917. https://doi.org/10.1002/ ijc. 25516

24. England PH. Cancer registration statistics, England: 2017. 2019.

25. Ben-Shlomo Y, Evans S, Ibrahim F, Patel B, Anson K, Chinegwundoh F, et al. The risk of prostate cancer amongst black men in the United Kingdom: the PROCESS cohort study. Eur Urol. 2008;53(1):99-105. https://doi.org/10.1016/j.eururo.2007.02.047

26. Lloyd T, Hounsome L, Mehay A, Mee S, Verne J, Cooper A. Lifetime risk of being diagnosed with, or dying from, prostate cancer by major ethnic group in England 2008-2010. BMC Med.. 2015;13:171. https://doi.org/10.1186/s12916-015-0405-5

27. Collin SM, Martin RM, Metcalfe C, Gunnell D, Albertsen PC, Neal D, et al. Prostate-cancer mortality in the USA and UK in 1975-2004: an ecological study. Lancet Oncol. 2008;9(5):445-52. https://doi. org/10.1016/S1470-2045(08)70104-9

28. Taitt HE. Global Trends and Prostate Cancer: A Review of Incidence, Detection, and Mortality as Influenced by Race, Ethnicity, and Geographic Location. Am J Mens Health. 2018;12(6):1807-23. https://doi.org/10.1177/1557988318798279

29. Mottet N, Bellmunt J, Bolla M, Briers E, Cumberbatch MG, De Santis M, et al. EAU-ESTRO-SIOG Guidelines on Prostate Cancer. Part 1: Screening, Diagnosis, and Local Treatment with Curative Intent. Eur Urol. 2017;71(4):618-29. https://doi.org/10.1016/j.eururo.2016.08.003

30. Patasius A, Innos K, Barchuk A, Ryzhov A, Leja M, Misins J, et al. Prostate cancer incidence and mortality in the Baltic states, Belarus, the Russian Federation and Ukraine. BMJ Open. 2019;9(10):e031856. https://doi.org/10.1136/bmjopen-2019-031856

31. Feuer EJ, Merrill RM, Hankey BF. Cancer surveillance series: interpreting trends in prostate cancer-part II: Cause of death misclassification and the recent rise and fall in prostate cancer mortality. J Natl Cancer Inst. 1999;91(12):1025-32. https://doi.org/10.1093/jnci/91.12.1025

32. Ha Chung B, Horie S, Chiong E. The incidence, mortality, and risk factors of prostate cancer in Asian men. Prostate Int.. 2019;7(1):1-8. https://doi.org/10.1016/j.prnil.2018.11.001

33. Sim HG, Cheng CW. Changing demography of prostate cancer in Asia. EurJ Cancer. 2005;41(6):834-45. https://doi.org/10.1016/j.ejca.2004.12.033

34. Baade PD, Youlden DR, Cramb SM, Dunn J, Gardiner RA. Epidemiology of prostate cancer in the Asia-Pacific region. Prostate Int. 2013;1(2):47-58. https://doi.org/10.12954/PI.12014

35. Zhang L, Yang BX, Zhang HT, Wang JG, Wang HL, Zhao XJ. Prostate cancer: an emerging threat to the health of aging men in Asia. Asian J Androl. 2011;13(4):574-8. https://doi.org/10.1038/ aja.2010.126 
36. Pathirana T, Hayen A, Doust J, Glasziou P, Bell K. Lifetime risk of prostate cancer overdiagnosis in Australia: quantifying the risk of overdiagnosis associated with prostate cancer screening in Australia using a novel lifetime risk approach. BMJ Open. 2019;9(3):e022457. https://doi.org/10.1136/ bmjopen-2018-022457

37. Zargar H, van den Bergh R, Moon D, Lawrentschuk N, Costello A, Murphy D. The impact of the United States Preventive Services Task Force (USPTSTF) recommendations against prostate-specific antigen (PSA) testing on PSA testing in Australia. BJU Int. 2017;119(1):110-5. https://doi. org/10.1111/bju.13602 
